5

\title{
Hydroperiod is the main driver of the spatial pattern of dominance in mangrove communities
}

\author{
BETH CRASE ${ }^{1 *}$, ADAM LIEDLOFF $^{2}$, PETER A. VESK $^{1}$, MARK A. BURGMAN $^{3}$ and \\ BRENDAN A. WINTLE ${ }^{1}$
}

${ }^{1}$ The Centre of Excellence for Environmental Decisions, School of Botany, University of Melbourne, Parkville 3010, Victoria, Australia

${ }^{2}$ CSIRO Ecosystem Sciences, Berrimah 0838, Northern Territory, Australia

${ }^{3}$ The Centre of Excellence for Risk Analysis, School of Botany, University of Melbourne, Parkville 3010, Victoria, Australia

* Corresponding author: Email address: Beth.Crase@nt.gov.au

Article type: Research paper

Short running header: Key factors influencing mangrove species distribution

15 ABSTRACT

6 Aim Many mangrove communities form bands parallel to the shoreline with each community

7 dominated by a single species. However, the key determinants of mangrove species

8 distribution across the intertidal zone are not well understood. We aimed to quantify the

relationship between species' dominance and the hydroperiod (defined as the duration of

20 inundation in a year), soil salinity and the salinity of inundating water for three dominant

1 species: Sonneratia alba, Rhizophora stylosa and Ceriops tagal. 
22 Location An extensive (20,000 ha), largely intact mangrove forest in northern Australia, of some note as mangrove forests are threatened globally.

Methods We related species dominance to the explanatory variables by applying two statistical modelling approaches: Generalised Linear Models (GLMs), where a set of competing models were evaluated; and Boosted Regression Tree models (BRTs), an approach able to automatically capture interactions and nonlinear relationships between variables.

Results and main conclusions Both GLM and BRT models achieved strong predictive performance for all species based on cross-validation, with ROCs above 0.85 for all species, and $88 \%$ of deviance explained for S. alba, $42 \%$ for $R$. stylosa and $35 \%$ for C. tagal. All models indicated that the hydroperiod was the key variable influencing distribution, followed by soil salinity. The salinity of inundating water was the least informative variable in the models. Ecological space, determined by gradients in hydroperiod and soil salinity, was partitioned between the three species with little overlap. As anticipated changes in sea level will alter the hydroperiod, our findings are critical for global forecasting of future distributions of mangrove communities, and for the design of mitigation and adaptation measures.

Key words: $\quad$ boosted regression tree; BRT; generalized linear model; GLM; hydroperiod; salinity; sea level rise; species dominance; species distribution; statistical models; tidal regime 
INTRODUCTION

Mangrove forests perform a critical role in maintaining a high diversity and abundance of fish in near-by reefs and seagrass meadows, store more carbon than most other forest types worldwide, and provide coastal protection from erosion caused by storm surge and tsunamis (Costanza et al., 1997; Mumby et al., 2004; Danielsen et al., 2005; Donato et al., 2011). Mangrove forests are threatened globally, due to clearing for aquaculture, agriculture, urban and industrial development (Giri et al. 2011; Valiela et al., 2001). Future sea levels are forecast to increase from 0.18 to $1.8 \mathrm{~m}$ by 2100 (Nicholls et al., 2007; Rahmstorf et al., 2007) with the potential to strongly affect mangrove forests. Sound management decisions and our understanding of mangrove ecology depend on characterizing the key factors influencing the distribution of mangrove species across the intertidal zone.

Many mangrove communities form bands parallel to the shoreline with each community dominated by a single species (Snedaker, 1982; Smith III, 1992). This striking spatial patterning of dominance, often referred to as "zonation" has been investigated using both field observations and glasshouse experiments, and although the spatial patterning in bands is simple, the relationship between mangrove species distribution and environmental drivers is complex (see for reviews Snedaker, 1982; Smith III, 1992; Krauss et al., 2008). The key environmental drivers proposed for mangrove species distribution include the salinity of the soil and inundating water (Ball, 1988a; Ukpong, 1991; Ball \& Pidsley, 1995; Bunt, 1996), the hydroperiod (Watson, 1928; Krauss et al., 2006), other soil physicochemical properties such as phosphorous and nitrogen, $\mathrm{pH}$, redox potential and sulphides (McKee, 1993; Matthijs et al., 1999; Feller et al., 2003; Krauss et al., 2006) and biotic interactions (Ball, 1988b; Clarke, 2004). 
Of these proposed environmental drivers of mangrove species distribution and dominance, the influence of salinity on mangrove species physiology and distribution has received the greatest research effort. However, it has been difficult to link the physiological response of species to their observed distribution within mangrove forests. For example, Ball and Pidsley (1995), Smith III (1988) and Ukpong (1991) found that experimentally determined growth optima did not match the soil salinity of areas occupied by the taxa within mangrove forests. Furthermore, correlations between soil salinity and species patterning have been demonstrated for only about one-third of mangrove species studied (Matthijs et al., 1999; Lovelock et al., 2005). Likewise, the salinity of inundating water along rivers was not shown to strongly relate to the observed spatial patterning of mangrove species (Bunt, 1996), and the relationship between plant species distribution or dominance and soil physicochemical properties such as phosphorous, nitrogen, $\mathrm{pH}$, redox potential and sulphides is inconsistent (McKee, 1993; Matthijs et al., 1999; Feller et al., 2003; Krauss et al., 2006).

Biological factors have also been proposed to influence mangrove zonation, and two of these hypotheses have been explored, and rejected. The first proposed that tidal sorting of propagules resulted in zonation (Rabinowitz, 1978), and was later disproven by several other studies including Sousa et al. (2007). The second hypothesis proposed that the selective predation of propagules by crabs caused the observed zonation and was supported at some locations but not at other, equally well zoned, locations (Smith et al., 1989; McGuinness, 1997). Finally, competition between mangrove species has been proposed (Ball, 1988b; Clarke, 2004), and tested in glasshouse experiments (Cardona-Olarte et al., 2006). CardonaOlarte and colleagues showed that two mangrove species responded differentially to treatments of salinity and hydroperiod (tidal and fixed flooding), and that one species had a competitive advantage over the other under low to mild stress by hydroperiod and salinity, but that this advantage was reduced under the high salinity and fixed flooding treatments. 
Where competitive interactions between species occur, the portion of an environmental gradient occupied by a species represents the realized niche of that species (Hutchinson, 1959; Austin \& Smith, 1989).

Hydroperiod has been largely overlooked in studies of the spatial distribution of mangrove species occurrence and dominance. The hydroperiod is the proportion of time a location is inundated (here called duration of inundation), and is determined by elevation, tidal frequency and amplitude. The influence of hydroperiod on mangrove distribution is still poorly known (Krauss et al., 2006), despite being proposed as a key factor more than 80 years ago (Watson, 1928). Experimental treatments simulating natural tidal amplitudes showed that species grew at different rates under different treatments (Ellison \& Farnsworth, 1997; Chen et al., 2005; He et al., 2007). For example, He et al. (2007), reported differing biomass, mortality and carbon allocation to roots, stems and leaves among mangrove species; and species ranked by experimentally determined inundation tolerance matched the pattern of species distribution for that location. Furthermore, differing growth responses and mortality to elevation (and therefore hydroperiod) were reported for seven species (Kitaya et al., 2002). However, little variation in mortality, establishment and growth rates was found among five species planted at low and high elevation sites (Clarke, 2004).

Species distribution models (SDMs) are a collection of statistical modelling approaches widely used to characterise and forecast plant and animal distributions (Zimmermann et al, 2010). However, we are unaware of studies using these techniques to investigate mangrove species distributions and their ecological drivers. While statistical models (such as SDMs) do not demonstrate the physiological or mechanistic basis for species distribution or dominance, experimental approaches, such as glasshouse trials, are limited because the complexity of a natural forest ecosystem cannot be replicated. As previous studies have indicated a mismatch between the experimentally identified salinity optima (or tolerance) and the natural 
distribution of mangrove species (eg. Smith III, 1988; Ball \& Pidsley, 1995), applying these statistical modelling approaches provides a useful way to investigate the relationship between species distribution and environmental conditions. Strong correlations identified in the field can be used for two broad purposes: firstly to identify which causal relationships to test experimentally, and secondly, to provide a basis for predictions of the global implications of sea level rise on mangroves ecosystems.

In this study we use spatially explicit statistical models to quantify the relationship between the spatial patterning of mangrove species' dominance and hydroperiod, soil salinity and water salinity. We derived the duration of inundation experienced at field sites from high precision, remotely sensed LiDAR (Light Detection and Ranging) data, and this is the first time such data have been used to explore the drivers of mangrove distribution. Our specific goals were to rank the influence of hydroperiod, soil salinity and water salinity on the dominance of three mangrove tree species, to identify interactions between variables and to characterise the partitioning of environmental gradients between species. We specifically aim to assess the influence of hydroperiod against other variables representing water salinity and soil salinity.

\section{METHODS}

\section{Study site}

The study was conducted in the mangrove forest (20, 400 ha) of Darwin Harbour in northern Australia (Fig. 1), a relatively undisturbed system representative of mangrove systems in the tropics (Brocklehurst \& Edmeades, 1996). Such undisturbed forests are of note because mangrove forests are a globally threatened ecosystem (Valiela et al., 2001). Extensive clearing particularly in the Asia-Pacific region (including Australia) has substantially reduced the extent of mangrove forests (Valiela et al., 2001). Darwin Harbour has semidiurnal, macro 
tides up to $8 \mathrm{~m}$, with mean spring and neap tides of approximately 6 and $3 \mathrm{~m}$, respectively (Williams et al., 2006). The upstream reaches of the harbour have low water salinity during the wet season due to fresh water run off and high salinity in the dry season due to the concentration of salts via evaporation (Williams et al., 2006). The maximum daily temperatures range from 30.5 to $33.3^{\circ} \mathrm{C}$, and the average annual rainfall of $1728 \mathrm{~mm}$ falls during the wet season from November to March (Australian Bureau of Meteorology, 2011).

\section{Focal species}

We investigated the relationship between the spatial patterning of dominance of three mangrove tree species Sonneratia alba Sm., Rhizophora stylosa Griff and Ceriops tagal Perr and a set of explanatory variables. These species were selected because they each form mono-specific communities in Darwin Harbour that are clearly evident from aerial photographs. Furthermore, these taxa dominate $82 \%$ of the mangrove forest as shown in maps produced by Brocklehurst and Edmeades (1996). Ceriops tagal dominates approximately $44 \%$ of the forest area, followed by the $R$. stylosa with $33 \%$, and finally $S$. alba covering 5\% (Brocklehurst \& Edmeades, 1996).

These taxa have large geographical ranges; Sonneratia alba and C. tagal are distributed along the eastern coast of Africa, through Asia and northern Australia to the Pacific, and R. stylosa occurs throughout Asia, northern Australia and the Pacific (Duke, 2006). Throughout their biogeographic distribution C. tagal usually occupies down-stream to intermediate estuarine locations of the high to mid intertidal zone, R. stylosa the down-stream estuarine areas in the mid to low intertidal and S. alba the down-stream areas of estuaries at the lowest tidal elevations (Duke 2006). Experiments have shown the growth optima (measured as net assimilation rate) across a gradient in salinity to be $25 \%$ of sea water for both $R$. stylosa and S. alba (Clough, 1984; Ball \& Pidsley, 1995), and at 50\% for C. tagal (Aziz \& Khan, 2001). 
Field experiments indicated differing flood tolerance, with $S$. alba reported as more flood tolerant than C. tagal (Kitaya et al., 2002).

Although recent work elevated C. tagal (Perr.) C. B. Rob var. tagal and C. tagal var. australis $\mathrm{C}$. T. White to the rank of species, discrimination between the two taxa is difficult without fertile material (Duke, 2006; Sheue et al., 2009). Therefore, in this study these taxa are referred to by their basyonym, Ceriops tagal Perr.

\section{Sampling methods}

A total of 201 sites were surveyed throughout Darwin Harbour, at least 100 meters apart (Fig. 1). Access constrained site selection and a map of the mangrove communities was used to target areas to survey (Brocklehurst \& Edmeades, 1996). We ensured a broad geographic spread of sites and site selection was stratified by vegetation type shown in maps of the Darwin Harbour mangoves (Brocklehurst \& Edmeades, 1996). Sites were selected a priori within three mapped vegetation types, each dominated by one of the focal species. To ensure sampling along the full gradients of soil and water salinity and the hydroperiod, an additional 43 sites were surveyed in areas not dominated by any of the three focal species. To avoid disturbed areas near industrial complexes and the city of Darwin, no sites were located on the north eastern side of East Arm. Where access to sites was constrained the sites were located as near to the selected location as possible. We recorded a site as dominated by one of the focal species where it contributed $70 \%$ or more to the total basal area. Forty three sites were dominated by S. alba, 59 dominated by R. stylosa and 56 by $C$. tagal. At each site we calculated the basal area (at $1.3 \mathrm{~m}$ ) of all tree species present using angle count sampling with two basal sweeps, $20 \mathrm{~m}$ apart, using a basal wedge (Bitterlich Gauge, factor 0.25 for all sites).

\section{Explanatory variables}


The explanatory variables selected for this study were the hydroperiod, soil salinity and three measurements of water salinity (dry season, wet season and the annual range in water salinity). The hydroperiod was selected as it has been long over looked as a possible factor and its role is poorly known (Krauss et al., 2008); and soil salinity and water salinity were included as the physiological effects of salinity on mangrove species are well established and generally regarded as an important influence on mangrove species establishment and growth (Snedaker, 1982; Smith III, 1992; Krauss et al., 2008). Other physicochemical soil properties were not explicitly included as their relationship to mangrove species distribution is weak and inconsistent (Smith III, 1992; Krauss et al., 2008).

To record soil salinity, soil samples were collected from the centre of each site, at a depth of $15-20 \mathrm{~cm}$ from the surface of the soil using a Russian-D sampler (where sites were reached on foot) or a custom made underwater corer (where sites were reached by boat). Soil samples were air dried, Milli-Q water added at a 1:5 soil to water ratio, shaken for one hour and allowed to settle following Rayment and Higginson (1992). The conductivity of the supernatant was measured with a conductivity probe (Activon model 301, Activon Scientific, Sydney, Australia) at an ambient temperature of $25^{\circ} \mathrm{C}$ in $\mathrm{mS} . \mathrm{cm}^{-1}$ and converted to salinity in parts per thousand (ppt).

Salinity values of the inundating water during the wet season and dry season were derived from interpolated surfaces for Darwin Harbour created from 222 locations sampled during the dry season and 674 locations sampled during the wet season between March 2009 and June 2010 (unpublished data Aquatic Health Unit, NT Government). Water salinity was measured with hydrolabs (Datasonde4a and DS5X, both from Hydrolab, Colorado, USA) $0.2 \mathrm{~m}$ below the water surface in parts per thousand (ppt). The two seasonal water salinity surfaces were created using diffusion interpolation (based on a heat diffusion equation) in ArcGIS (v10, ESRI 2011). Values of water salinity were extracted from these surfaces for each of the 201 
field sites. An additional water salinity variable was calculated by taking the difference

217 between dry season and wet season salinity, and represents the range in water salinity. Before

fitting to the models, the three water salinity variables were tested for correlations and as they were highly correlated (Pearson's product moment correlations $>0.9, \mathrm{p}<0.001$ ), we selected only the wet season water salinity variable to fit to the models as it had a greater range of values across the harbour ( 5 to $31.25 \mathrm{ppt}$ ) in comparison with the dry season (33.00 to 37.07 ppt).

Hydroperiod was calculated from the elevation above sea level for each site derived from remotely sensed LiDAR data collected for Darwin Harbour in 2009. The LiDAR product we used had been processed to remove noise and represents ground elevation only and has vertical accuracy of $0.01 \pm 0.15 \mathrm{~m}$, and a horizontal resolution of $0.21 \mathrm{~m}$ (Temby, 2009). The LiDAR elevations were converted from Australian Height Datum to Darwin Port Datum (Lowest Astronomical Tide) by subtracting 4.105 m (Australian Baseline, 2011). Tidal heights in Darwin Harbour, recorded every 20 minutes for a year by the Darwin tidal gauging station, were grouped into $1 \mathrm{~cm}$ elevation classes (D. Williams, unpublished data). The tide heights for a year were used to incorporate the annual, monthly and seasonal variation in tidal amplitude for the study area. We calculated the duration of inundation for each elevation class, which ranged from $0 \%$ (never inundated) to $100 \%$ (always inundated), then matched the elevation of each survey site (as indicated by LiDAR) to the vertical elevation class and extracted the percent of time each survey site is inundated.

\section{Statistical analyses}

Sets of statistical models were developed to describe the probability of dominance by $C$. tagal, R. stylosa or S. alba. We modelled the dominance of these species, rather than species 
distribution, because it is the dominance that produces the banded patterning of mangrove forests. Statistical models relate the response variable (the dominance or non-dominance of each species) to the set of explanatory variables (soil salinity, wet season water salinity and hydroperiod). To ensure robust model inference the explanatory variables fitted to the models should be independent and before fitting these three explanatory variables to models, they were tested for pair wise correlations with Pearson's product moment correlations.

We used two statistical modelling approaches, Generalised Linear Models (GLMs) and

Boosted Regression Tree (BRT) models to increase our confidence in the inference arising from the statistical analyses and to exploit the strengths of the two approaches: the interpretability of GLMs and the ability to automatically capture interactions and complex nonlinear relationships of BRT models (De'ath, 2007; Elith et al., 2008). As the data used in this study are binary and follow a Bernoulli distribution, a logit link function was used in the models (McCullagh \& Nelder, 1983). Three variables were fitted to GLMs using all combinations of linear, quadratic terms and interaction terms and the best model selected based on Akaiki's Information Criteria (AIC, Akaike, 1974). AIC is a measure of the parsimony of models based on a trade off between deviance reduction and the number of parameters fitted in the model. A full list of the GLM models fitted is provided as Development Core Team, 2011).

BRT models are a machine learning tool that combines two algorithms (Breiman, 1996; De'ath, 2007). The first generates trees by recursive binary splits, with explanatory variables and split points selected to minimize prediction errors. The second algorithm, called boosting, combines the trees produced by the first algorithm. The first tree is fitted to the data, the second tree is fitted to the residuals of the first tree, the third tree is fitted to the residuals of the second tree, and so on. Each tree selected for fitting is the one that produces the greatest 
reduction in deviance. Interactions between explanatory variables are controlled by setting the tree complexity where a value of one does not allow any interactions between variables.

The relative importance of each variable, within a model, is reported by calculating the number of times the variable is selected as the basis for a bifurcation by the fitting algorithm and scaled out of 100 (Elith et al. 2008). A tree complexity of three was used to allow some interaction between variables fitted to the model. The models were developed with a learning rate set to produce a minimum of 1000 trees using code from Elith et al. (2008) and the gbm library (Ridgeway, 2006) in R (vers 2.13.1; R Development Core Team, 2011).

We calculated two cross validated model performance metrics, the Area Under Curve (AUC) and the percent of deviance explained for the GLMs and BRT models (Guisan \& Zimmermann, 2000; Pearce \& Ferrier, 2000). The AUC combines the trade off between sensitivity (the true positive proportion) against the false positive proportion (Swets, 1988). An AUC score of 0.5 indicates that the model will correctly rank sites that are actually dominated by the focal species above sites not dominated by the focal species $50 \%$ of the time, and an AUC of 0.7 indicates the minimum acceptable accuracy of prediction (Pearce \& Ferrier, 2000). The deviance explained by the model shows the goodness of fit between modelled and observed values, and reflects the match between actual and predicted frequency of dominance of the focal species (Ferrier \& Watson, 1997). The deviance explained is null deviance minus residual deviance scaled by the null deviance, where the null deviance is the deviance of the model with only the intercept fitted, and residual deviance is the deviance remaining unexplained by the model when predictor variables are fitted (Guisan \& Zimmermann, 2000). We used ten-fold cross validation, whereby the data were randomly partitioned into ten subsets, the models fitted to nine of the ten subsets and accuracy determined by comparing model predictions to the tenth subset of held out data (Stone, 1974). This process was cycled through until each model had been fitted and tested ten times. 
As model predictions were tested against the held out portion of data during the cross validation procedure and not on the data used for fitting the model the assessment of model performance is more realistic than testing on the data used to fit the models. AICs are provided for the GLMs but not for the BRT models as they rely on degrees of freedom which cannot be calculated for complex modelling approaches such as BRT (Elder, 2003).

\section{RESULTS}

The mean hydroperiod differed among sites dominated by each species (Fig. 2). Sites occupied by $S$. alba had the longest mean hydroperiod (inundated $68.8 \%$ of the year), $R$. stylosa had an intermediate hydroperiod (20.7\%) and C. tagal had the shortest hydroperiod (5.1\%). The mean soil salinity associated with each species shows a different pattern, with $S$. alba occupying sites with the lowest soil salinity (27.04 ppt), followed by C. tagal (32.61 ppt) and R. stylosa in the sites with the highest mean soil salinity (38.61 ppt) (Fig. 2). The salinity of the inundating water was greater at sites dominated by $S$. alba than sites dominated by the other two species, with a mean wet season water salinity of $25.05 \mathrm{ppt}$ for $S$. alba, and 21.42 and $21.23 \mathrm{ppt}$ for $R$. stylosa and C. tagal respectively.

The three explanatory variables (soil salinity, wet season water salinity and hydroperiod) were tested for pair wise correlation with Pearson's product moment correlation and found to be uncorrelated ( $\mathrm{p}$-values $>0.05$ ). Therefore, all three were fitted to the models. The BRT models outperformed the GLMs for two of the three species as AUC scores were higher for R. stylosa and C. tagal BRT models (Table 1). The percent of deviance explained indicated that GLMs with quadratic and interaction terms had a performance similar to that of the BRT models (Table1). More deviance was explained by the GLM than the BRT for S. alba $(86.1 \%$ GLM, 79.2\% BRT), far more by the BRT model than by the GLM for $R$. stylosa (25.6\% 
GLM, $42.4 \%$ BRT) and a similar amount by both the models of $C$. tagal dominance $(34.2 \%$

GLM, 31.4\% BRT).

Model performance was strong for all three species (Table 1), showing that the variables included in the models explain much of the relationship between the environment and species dominance. Hydroperiod was identified as significant in the GLMs of all three species $(\mathrm{p}<0.01)$, while water salinity was not significant in any of them (Table 1). For the BRT models, hydroperiod was also the most important variable for species dominance for all species (relative variable importance ranged from 48.6 to 90.1 ), followed by soil salinity ( 7.5 to 46.3 ) and finally wet season water salinity (2.4 to 5.2) (Fig. 3).

The plots of the fitted functions of the BRT models show that $S$. alba dominance was dependent on both hydroperiod and soil salinity, while the other two species were less influenced by soil salinity (Fig. 3). The probability of dominance by S. alba peaked when the hydroperiod was above $40 \%$ of the time, whereas $R$. stylosa peaked between about 10 and $30 \%$ and C. tagal showed a peak when inundation was below about $10 \%$. Thus each species occupies a different portion of the gradient in the duration of inundation. A less distinct relationship is shown between the probability of species dominance and soil salinity (Fig. 3). Sonneratia alba had a higher probability of dominance with low soil salinity (0 to $35 \mathrm{ppt})$, while for $R$. stylosa the opposite relationship was found, where the probability of dominance is higher when soil salinity is above 30 ppt. There was a weak relationship between $C$. tagal dominance and soil salinity.

The relationship between species dominance and the explanatory variables was generally shown to be similar in the BRT fitted functions (Fig. 3) and the values of the GLM parameters (Table 2). In the GLMs, the quadratic term for hydroperiod was significant and negative for $S$. alba and $R$. stylosa showing that although there is a positive relationship with hydroperiod, once the duration of inundation is high the probability of dominance declines. 
Ceriops tagal dominates vegetation at higher elevations and is positively associated with soil salinity (as shown by the significant positive values in the GLM, Table 2), but the probability of dominance declines with high soil salinity, as indicated by the significant negative value of the quadratic soil salinity term. In contrast, the BRT models showed no decline in the probability of $C$. tagal dominance with higher soil salinity.

The probability of dominance by the three mangrove species, as determined by the duration of the hydroperiod and soil salinity is represented in 3-dimensional plots in Fig. 4. These plots illustrate the strong relationship between dominance of $S$. alba and both hydroperiod and soil salinity. Sonneratia alba is highly unlikely to dominate areas where the duration of inundation is less than $40 \%$ and soil salinity exceeds about 35 ppt, as shown in Fig. 4a. Both R. stylosa and C. tagal dominance are less influenced by soil salinity than S. alba, and there is a very marked increase in probability of dominance of these species along the gradient in the duration of hydroperiod (Fig. 4b, c). The gradient in hydroperiod is partitioned between the species as locations inundated more than $40 \%$ of the time more likely to be dominated by S. alba, locations inundated $10-40 \%$ R. stylosa dominates and locations with a hydroperiod of less than $10 \%$ are more likely to be dominated by C. tagal.

Interactions between hydroperiod and soil salinity and between hydroperiod and water salinity were significant in the GLMs for R. stylosa and C. tagal (Table 2). Ceriops tagal dominance had a negative relationship with hydroperiod and a positive relationship with soil salinity, but the effects of hydroperiod was not so marked at high soil salinity. The GLM's for S. alba contained no significant interaction terms, and hydroperiod had, by far, the strongest relationship with $S$. alba dominance. 
The analyses presented here provide unique insight into mangrove ecology because they provide, for the first time, spatially explicit statistical models quantifying the relationship between dominant mangrove species and a set of candidate explanatory variables which includes the hydroperiod derived from LiDAR data. Thus, they fill an important gap in the empirical study of mangrove ecology. Species dominance was most influenced by the hydroperiod followed by soil salinity and these relationships were nonlinear. The least influential variable was salinity of inundating water, concurring with previous studies (Bunt, 1996; Takaki et al., 2003). The mangrove species partitioned the gradient in hydroperiod, and to a lesser extent, the gradient in soil salinity. We found that $C$. tagal had the greatest probability of dominance at locations where the hydroperiod was less than $10 \%, R$. stylosa between 10 and $40 \%$, and $S$. alba dominated areas inundated more than $50 \%$ of the time. Experiments investigating the growth of mangrove seedlings under a range of hydoperiods found that in low elevation treatments, most $C$. tagal seedlings died within a year while the $S$. alba seedlings survived (Kitaya et al. 2002). This agrees with our study, that S. alba dominates areas with the greatest hydroperiod (low elevations), while C. tagal dominated locations with the lowest duration of inundation (high elevations).

In our study the hydroperiod was the most important explanatory variable in the models of mangrove dominance. There are two mechanisms by which the hydroperiod acts to influence mangrove growth and therefore distribution. First, the direct effects of flooding reduce the oxygen available to roots and reduce the rate of aerobic metabolism and water use efficiency (Naidoo, 1985; MccKee, 1996). Secondly, phytotoxins such as reduced forms of iron, manganese and sulphides build up in flooded, anoxic soils, and these affect plant growth by inhibiting photosynthetic gas exchange and root oxygen (Nickerson and Thibodeau, 1985; Youssef \& Saenger, 1998; McKee, 1993). Studies have shown a differential growth response of mangrove species to flooding treatments without separating the direct effects of inundation 
and the effects of soil phytotoxins (eg He et al. 2007). McKee (1993) separated the effects of inundation and sulphide and found that growth and biomass allocation differed between two mangrove species. The statistical modelling of the spatial distribution of mangrove dominants applied here illustrates that there is no need to partition the direct effect of flooding from the accumulation of soil phytotoxins as the hydroperiod controls both these mechanisms.

We found that the gradient in hydroperiod was clearly partitioned between the focal species, with less decisive partitioning of the gradient in soil salinity. As our data were collected from the distribution of taxa in a natural ecosystem, the partitioning of the gradients reported here are based on observations of a sub-set of the realized niche, not the fundamental niche sensu Hutchinson (1959), see also Colwell and Rangel (2009). We specify 'subset' because the species only dominate some fraction of the sites that they occupy. Therefore, the statistical models implicitly include the effects of competition between the species. The steep decline in C. tagal dominance when the hydroperiod exceeds $10 \%$ could be related to competition with R. stylosa rather than a threshold in physiological tolerance to inundation (Fig. 3). There are few studies on the effects of hydroperiod and interspecific competition (Cardona-Olarte et al., 2006), but these are needed to partition the effects of competition from the direct physiological effects of hydroperiod.

Our findings allow a reinterpretation of the substantial, and often conflicting literature on the effect of salinity on mangrove distribution across intertidal areas. Mangrove species have a range of morphological and physiological adaptations to saline environments (Parida \& Jha, 2010) and the differences in salt tolerance between taxa lead to differential growth rates with increasing salinity (Ball, 1988a; Smith III, 1988; Ball \& Pidsley, 1995). However, previous studies have not been able to demonstrate a link between the demonstrated physiological response of taxa and their observed distribution within mangrove forests. For example, 
optimum salinity for growth of mangrove species in glasshouse experiments did not correspond to species' distribution along a natural salinity gradient (Smith III, 1988; Ball \& Pidsley, 1995). Our results suggest that the hydroperiod overwhelms the effects of soil salinity on plant physiology and explains the previously reported weak and inconsistent relationship between soil salinity and species patterning (Matthijs et al., 1999; Lovelock et al., 2005).

For Darwin Harbour there were no correlations between the explanatory variables fitted to the models (i.e. among soil salinity, wet season water salinity and hydroperiod). Across a single transect it is possible for soil salinity to be inversely related to the hydroperiod as evaporation concentrates the salts at locations of higher elevation (Smith, 1992). However, when a study area is considered in its entirety in all directions across the landscape then correlations between soil salinity and elevation are lost. Soil salinity is also determined by the salinity of the inundating water which varies from fresh to sea water depending on location along an upstream to downstream axis, and also by distance to local fresh water inputs from runoff and springs (Duke et al., 1998). In addition, soil salinity can also greatly vary with depth, for example, a single location can range from 10 to $50 \mathrm{ppt}$ at different depths (Marchand et al., 2004). Thus soil salinity has a high spatial variability (in three dimensions: upstream downstream, elevation above sea level, and with depth of soil) and high temporal variability on daily (tidal), seasonal (rainfall and tidal) and yearly cycles. The ecological rationale for the action of the hydroperiod is sufficient to explain the lack of correlation between soil salinity, hydroperiod and water salinity for Darwin Harbour.

The statistical modelling approach applied here provides a powerful technique for quantifying relationships between species dominance and explanatory variables. Such species distribution models are widely used in ecology, although this is the first example for a 
mangrove ecosystem. Mangrove field work is difficult and can be dangerous where saltwater crocodiles occur (e.g. northern Australia), and we advocate reanalysing existing datasets using the statistical approaches used here to test the generality of the patterns and relationships we have presented in this study. Exploring existing datasets in new ways may prompt further insights into mangrove dominance, community assembly and distribution. While species distribution models are commonly used to model species occurrence, we provide a novel approach by modelling the distribution of species dominance. Modelling the spatial dominance of keystone species in other vegetation types may lead to new insights into the processes structuring communities.

The most important implication of our findings about the primacy of the hydroperiod in influencing the spatial patterning of species dominance, is that under conditions of sea level rise we can expect extensive spatial restructuring of mangrove communities within the forests. Such restructuring may have a cascade of effects on coastal erosion, fisheries and carbon sequestration. This study hinges on the use of LiDAR data which have not yet been collected for many areas supporting mangrove forest, for example in the developing world and in the vast, remote areas of northern Australia. LiDAR has a high vertical precision (to within $1 \mathrm{~cm})$ and a fine grain $(1 \times 1 \mathrm{~m}$ tiles) enabling detailed forecasts of the spatial changes in mangrove distribution. However, such datasets are massive (the whole of Darwin Harbour mangrove forest LiDAR is in excess of $6 \mathrm{~GB}$ ) and the ability of software to handle them efficiently or to handle them at all could limit spatial analyses.

454 The relationships we have quantified can be used to forecast the spatial shift in species 455 dominance in response to sea level rise, critical for planning coastal development and 456 infrastructure, fisheries management, mangrove rehabilitation projects and management 457 activities directed towards mitigation and adaptation to sea level driven changes. Our findings 
indicate that future experimental studies that aim to identity influences on mangrove species distributions should focus on the hydroperiod rather than the effects of salinity.

460

461

462

463

464

465

466

467

468

469

470

471

472

473

474

475

476

477

478

479

480

481

\section{ACKNOWLEDGEMENTS}

This project was supported by the Australian Government through the National Environment Research Program Environmental Decision Hub. BC is supported by an Australian Postgraduate Award and BAW by an ARC Future Fellowship. We are grateful for the assistance of Yusuke Fukuda in manipulating spatial data, and Lindley McKay, Murray Schneider, Julia Fortune and Matt Majid for assistance with field work.

\section{REFERENCES}

Austin, M. P. \& Smith, T. M. (1989) A new model for the continuum concept. Vegetatio, 83, $35-47$.

Australian Baseline (2011) Australian Baseline Sea Level Monitoring Project File Information and Instructions, IDO71014 (Northern Territory), Bureau of Meteorology http://www.bom.gov.au/oceanography/projects/abslmp/data/data.shtml

Australian Bureau of Meteorology (2011) Climate statistics for Australian locations, Bureau of Meteorology http://www.bom.gov.au/climate/averages/tables/cw_014015.shtml

Aziz, I. \& Khan, M. A. (2001) Experimental assessment of salinity tolerance of Ceriops tagal seedlings and saplings from the Indus delta, Pakistan. Aquatic Botany, 70, 259-268.

Akaike, H. (1974) A new look at the statistical model identification. Institute of electrical and electronics engineers transactions on automatic control, 19, 716-723.

Ball, M. C. (1988a) Salinity tolerance in the mangroves Aegiceras corniculatum and Avicennia marina. 1. Water-use in relation to growth, carbon partitioning and salt balance. Australian Journal of Plant Physiology, 15, 447-464. 
Ball, M. C. (1988b) Ecophysiology of mangroves. Trees, 2, 129-142.

Ball, M. C. \& Pidsley, S. M. (1995) Growth-responses to salinity in relation to distribution of 2 mangrove species, Sonneratia alba and S. lanceolata, in northern Australia. Functional Ecology, 9, 77-85.

Breiman, L. (1996) Bagging predictors. Machine Learning, 24, 123-140.

Brocklehurst, P. \& Edmeades, B. (1996) The mangrove communities of Darwin Harbour. Department of Lands, Planning and Environment, Resource Capability Assessment Branch, Northern Territory Government, Darwin.

Bunt, J. S. (1996) Mangrove zonation: An examination of data from seventeen riverine estuaries in tropical Australia. Annals of Botany, 78, 333-341.

Cardona-Olarte, P., Twilley, R. R., Krauss, K. W. \& Rivera-Monroy, V. (2006) Responses of neotropical mangrove seedlings grown in monoculture and mixed culture under treatments of hydroperiod and salinity. Hydrobiologia, 569, 325-341.

Chen, L. Z., Wang, W. Q. \& Lin, P. (2005) Photosynthetic and physiological responses of Kandelia candel L. Druce seedling to duration of tidal immersion in artificial seawater. Environmental and Experimental Botany, 54, 256-266.

Clarke, P. J. (2004) Effects of experimental canopy gaps on mangrove recruitment: lack of habitat partitioning may explain stand dominance. Journal of Ecology, 92, 203-213.

Clough, B. F. (1984) Growth and salt balance in the mangroves Avicennia marina (Forsk.) Vierh. and Rhizophora stylosa Griff. in relation to salinity. Australian Journal of Plant Physiology, 11, 419-430. 
503

504

505

506

507

508

509

510

511

512

513

514

515

516

517

518

519

520

521

522

523

Colwell, R. K. \& Rangel, T. F. (2009) Hutchinson's duality: The once and future niche. PNAS, 106, 19651-19658.

Costanza, R., d’Arge, R., deGroot, R., Farber, S., Grasso, M., Hannon, B., Limburg, K., Naeem, S., O’Neill, R. V., Paruelo, J., Raskin, R. G., Sutton, P. \& van den Belt, M. (1997) The value of the world's ecosystem services and natural capital. Nature, 387, 253-260.

Danielsen, F., Sørensen, M. K, Olwig, M. F., Selvam, V., Parish, F., Burgess, N. D., Hiraishi, T., Karunagaran, V. M., Rasmussen, M. S., Hansen, L. B., Quarto, A. \& Suryadiputra, N. (2005) The Asian tsunami: A protective role for coastal vegetation. Science, 310, 643-643.

De'ath, G. (2007) Boosted trees for ecological modeling and prediction. Ecology, 88, 243251.

Donato, D. C., Kauffman, J. B., Murdiyarso, D., Kurnianto, S., Stidham, M. \& Kanninen, M. (2011) Mangroves among the most carbon-rich forests in the tropics. Nature Geoscience, 4, 293-297.

Duke, N. C., Ball, M. C., \& Ellison, J. C. (1998) Factors influencing biodiversity and distributional gradients in mangroves. Global Ecology and Biogeography Letters, 7, 27 47.

Duke, N. C. (2006) Australia's Mangroves. University of Queensland, Brisbane.

Elder (2003) The generalization paradox of ensembles. Journal of Computational and Graphical Statistics, 12, 853-864. 
Elith, J., Leathwick, J. R. \& Hastie, T. (2008) A working guide to boosted regression trees. Journal of Animal Ecology, 77, 802-813.

Ellison, A. M. \& Farnsworth, E. J. (1997) Simulated sea level change alters anatomy, physiology, growth, and reproduction of red mangrove (Rhizophora mangle L.). Oecologia, 112, 435-446.

ESRI (2011) ArcGIS Desktop, release 10. Environmental Systems Research Institute Redlands, California, USA.

Feller, I. C., McKee, K. L., Whigham, D. F. \& O'Neill, J. P. (2003) Nitrogen vs. phosphorus limitation across an ecotonal gradient in a mangrove forest. Biogeochemistry, 62, 145175.

Ferrier, S. \& Watson, G. (1997) An evaluation of the effectiveness of environmental surrogates and modelling techniques in predicting the distribution of biological diversity. New South Wales Parks and Wildlife, Biodiversity Group, Environment Australia.

Giri, C., Ochieng, E., Tieszen, L. L., Zhu, Z., Singh, A., Loveland, T., Masek, J. \& Duke N. (2011) Status and distribution of mangrove forests of the world using earth observation satellite data. Global Ecology and Biogeography, 20, 154-150.

Guisan, A. \& Zimmermann, N. E. (2000) Predictive habitat distribution models in ecology. Ecological Modelling, 135, 147-186.

He, B., Lai, T., Fan, H., Wand, W. Q. \& Zheng, H. (2007) Comparison of flooding tolerance in four mangrove species in a diurnal tidal zone in the Beibu Gulf. Estuarine, Coastal and Shelf Science, 74, 254-262. 
546 Hutchinson, G. E. (1959) Hommage to Santa Rosalia, or why are there so many kinds of animals? American Naturalist, 93, 145-159.

548

549

550

551

552

553

554

555

556

557

558

559

560

561

562

563

564

565

566

567

Kitaya, Y., Jintana, V., Piriyayotha, S., Jaijing, D., Yabuki, K., Izutani, S., Nishimiya, A. \& Iwasaki, M. (2002) Early growth of seven mangrove species planted at different elevations in a Thai estuary. Trees - Structure and Function, 16, 150-154.

Krauss, K.W., Doyle, T.W., Twilley, R.R., Rivera-Monroy, V.H. \& Sullivan, J.K. (2006) Evaluating the relative contributions of hydroperiod and soil fertility on growth of south Florida mangroves. Hydrobiologia, 569, 311-324.

Krauss, K. W., Lovelock, C. E., McKee, K. L., López-Hoffman, L., Ewe, S. M. L. \& Sousa, W. P. (2008) Environmental drivers in mangrove establishment and early development: A review. Aquatic Botany, 89, 105-127.

Lovelock, C. E., Feller, I. C., McKee, K. L. \& Thompson, R. (2005) Variation in mangrove forest structure and sediment characteristics in Bocas del Toro, Panama. Caribbean Journal of Science, 41, 456-464.

Marchand, C., Baltzer, F., Lallier-Vergès, E. \& Albéric, P. (2004) Pore-water chemistry in mangrove sediments: relationship with species composition and developmental stages (French Guiana). Marine Geology, 208, 361-381.

Matthijs, S., Tack, J., van Speybroeck, D. \& Koedam, N. (1999) Mangrove species zonation and soil redox state, sulphide concentration and salinity in Gazi Bay (Kenya), a preliminary study. Mangroves and Salt Marshes, 3, 243-249.

McCullagh, P. \& Nelder, J. A. (1983) Generalized Linear Models. Chapman and Hall, London. 
McGuinness, K. A. (1997) Seed predation in a tropical mangrove forest: A test of the dominance-predation model in Northern Australia. Journal of Tropical Ecology, 13, 293-302.

McKee, K. L. (1993) Soil physicochemical patterns and mangrove species distribution: Reciprocal effects? Journal of Ecology, 81, 477-487.

McKee, K. L. (1996) Growth and physiological responses of neo-tropical seedlings to root zone hypoxia. Tree Physiology, 15, 883-889.

Mumby, P. J., Edwards, A. J., Arias-González, J. E., Lindeman, K. C., Blackwell, P. G., Gall, A., Gorczynska, M. I., Harborne, A. R., Pescod, C. L., Renken, H., Wabnitz, C. C. C. \& Llewellyn, G. (2004) Mangroves enhance the biomass of coral reef fish communities in the Caribbean. Nature, 427, 533-536.

Naidoo, G. (1985) Effects of water logging and salinity on plant water relations and on the accumulation of solutes in three mangrove species. Aquatic Botany, 22, 133-143.

Nicholls, R. J., Wong, P. P., Burkett, V. R., Codignotto, J. O., Hay, J. E., McLean, R. F., Ragoonaden, S. \& Woodroffe, C. D. (2007) IPCC. Coastal systems and low-lying areas. Climate Change 2007: Impacts, Adaptation and Vulnerability, Contribution of Working Group II to the Fourth Assessment Report of the Intergovernmental Panel on Climate Change (ed. by M. L. Parry, O.F. Canziani, J.P. Palutikof, P.J. van der Linden and C.E. Hanson), pp. 315-356. Cambridge University Press, Cambridge.

Nickerson, N. H., \& Thibodeau, F. R. (1985) Association between pore water sulphide concentrations and the distribution of mangroves. Biogeochemistry, 1, 183-192.

Parida, A. K. \& Jha, B. (2010) Salt tolerance mechanisms in mangroves: a review. Trees, 24, 199-217. 
Pearce, J., \& Ferrier, S. (2000) Evaluating the predictive performance of habitat models developed using logistic regression. Ecological Modelling, 133, 225-245.

R Development Core Team (2011) R: A language and environment for statistical computing. R Foundation for Statistical Computing, Vienna.

Rabinowitz, D. (1978) Early growth of mangrove seedlings in Panama, and an hypothesis concerning the relationship of dispersal and zonation. Journal of Biogeography, 5, 113133.

Rayment, G. E. \& Higginson, F. R. (1992) Australian Laboratory Handbook of Soil and Water Chemical Methods. Inkata Press, North Ryde.

Rahmstorf, S., Cazenave, A., Church, J. A., Hansen, J. E., Keeling, R. F., Parker, D. E. \& Somerville, R. C. J. (2007) Recent climate observations compared to projections. Science, 316, 709-709.

Ridgeway, G. (2006) Generalized boosted regression models. Documentation on the R package 'gbm', version 1.5-7 http://www.i-pensieri.com/gregr/gbm.shtml.

Sheue, C. R., Yang, Y. P., Liu, H. Y., Chou, F. S., Chang, H. C., Saenger, P., Mangion, C. P., Wightman, G., Yong, J. W. H. \& Tsai, C. C. (2009) Re-evaluating the taxonomic status of Ceriops australis (Rhizophoraceae) based on morphological and molecular evidence. Botanical Studies, 50, 89-100.

Smith III, T. J. (1988) Differential distribution between sub-species of the mangrove Ceriops tagal: Competitive interactions along a salinity gradient. Aquatic Botany, 32, 79-89.

Smith, T. J., Chan, H. T., McIvor, C. C., Robblee, M. B. (1989) Comparisons of seed predation in tropical, tidal forests from three continents. Ecology, 70, 146-151. 
613 Smith III, T. J. (1992) Forest Structure. Tropical Mangrove Ecosystems (ed. by A. I.

614 Roberston and D.M. Alongi), pp. 329. American Geophysical Union, Washington D.C.

615 Snedaker, S. C. (1982) Mangrove species zonation: why? Dr W. Junk, The Hague.

616 Sousa, W. P., Kennedy, P., G., Mitchell, B. J. \& Ordóñez, B. M. (2007) Supply-side ecology

617 in mangroves: Do propagule dispersal and seedling establishment explain forest

$618 \quad$ structure? Ecological Monographs, 77, 53-76.

619 Stone, M. (1974) Cross-validatory choice and assessment of statistical predictions. Journal of 620 the royal statistics society, series $B, \mathbf{3 6}, 111-147$.

621 Swets, J. A. (1988) Measuring the accuracy of diagnostic systems. American Association for the Advancement of Science, 240, 1285-1293.

623

Takaki, T., Balagas, P. O. \& Hirohiko, M. (2003) Relationships between distribution of mangrove species and salinity level along the tidal rivers in the Philippines. Japanese Journal of Forest Environment, 45, 65-74.

626

627

Temby, O. (2009) Project report for aerial LiDAR survey of Darwin and surrounds. Fugro Spatial Solutions Pty Ltd, Perth.

Ukpong, I. E. (1991) The performance and distribution of species along soil-salinity gradients of mangrove swamps in south-eastern Nigeria. Vegetatio, 95, 63-70.

Valiela, I., Bowen, J. L. \& York, J. K. (2001) Mangrove forests: One of the world's threatened major tropical environments. Bioscience, 51, 807-815. 6, 1-275. 
634 Williams, D., Wolanski, E. \& Spagnol, S. (2006) Hydrodynamics of Darwin Harbour. The

635 environment in Pacific Harbours (ed. by E. Wolanski), pp. 461-476. Springer, The

636 Hague.

637

Youssef, T., \& Saenger, P. (1998) Photosynthetic gas exchange and accumulation of

638 phytotoxins in mangrove seedlings in response to soil physico-chemical characteristics

639 associated with waterlogging. Tree Physiology, 18, 317-324.

640

Zimmermann, N. E., Edwards, T. C., Graham, C. H., Pearman, P. B. \& Svenning, J-C (2010)

641 New trends in species distribution modelling. Ecography, 33, 985-989.

642

643

644 BIOSKETCH: Beth Crase is a tropical botanist interested in spatial analysis and statistical 645 modelling within landscape ecology and biogeography, with a particular focus on forecasting 646 the impacts of sea level rise on coastal plant communities. 
Table 1. Performance metrics for GLM and BRT models of Sonneratia alba, Rhizophora stylosa or Ceriops tagal dominance in Darwin Harbour, northern Australia. Ten-fold cross-validation scores are provided for AUC and percent of deviance explained (\% DE) \pm standard error (s.e.). The first five GLMs are a standard set of models provided for each species, and the sixth model is the best of a set of 91 GLMs as indicated by Akaike's information criteria (AIC), marked by an asterisk. GLMs were fitted with all combinations of the explanatory variables: hydroperiod (h), soil salinity (s) and wet season water salinity (w), quadratic term (denoted by superscript 2) and interactions between variables (denoted by a colon). All models fitted are shown in SUPPLEMENTARY MATERIAL. BRT models are the final two models illustrated and were fitted with all explanatory variables, with and without interactions between the variables. AIC scores are not able to be calculated for BRT models

Model

$\begin{array}{lll}\text { Mean AUC } \pm & \text { Mean \% } & \text { AIC } \\ \text { s.e. } & \text { DE } \pm \text { s.e. } & \end{array}$

Sonneratia alba

GLM:

$\begin{array}{lccc}\text { Hydroperiod (h) } & 0.95 \pm 0.02 & 60.2 \pm 0.9 & 87.4 \\ \text { soil salinity (s) } & 0.54 \pm 0.04 & 0.2 \pm 0.03 & 212.3 \\ \text { water salinity (w) } & 0.63 \pm 0.05 & 5.0 \pm 0.2 & 202.4 \\ \mathrm{~h}+\mathrm{s}+\mathrm{w} & 0.98 \pm 0.01 & 71.3 \pm 0.8 & 68.2 \\ \mathrm{~h}+\mathrm{s}+\mathrm{w}+\mathrm{h}^{2}+\mathrm{s}^{2}+\mathrm{w}^{2}+\mathrm{h}: \mathrm{s}+\mathrm{h}: \mathrm{w}+\mathrm{w}: \mathrm{s} & 0.99 \pm 0.01 & 88.2 \pm 0.5 & 45.6 \\ \mathrm{~h}+\mathrm{s}+\mathrm{h}^{2} * & 0.99 \pm 0.04 & 86.1 \pm 0.4 & 37.4\end{array}$


BRT:

no interactions

$0.99 \pm 0.01 \quad 77.9 \pm 6.3 \quad$ n.a.

interactions

$0.99 \pm 0.01 \quad 79.2 \pm 5.8 \quad$ n.a.

\section{Rhizophora stylosa}

GLM:

hydroperiod

$0.31 \pm 0.03 \quad 0.2 \pm 0.1 \quad 246.9$

soil salinity

$0.70 \pm 0.66 \quad 7.7 \pm 0.5 \quad 228.8$

water salinity

$0.53 \pm 0.03 \quad 0.3 \pm 0.1 \quad 248.6$

$\mathrm{h}+\mathrm{s}+\mathrm{w}$

$0.73 \pm 0.03$

$8.6 \pm 0.5 \quad 230.9$

$h+s+w+h^{2}+s^{2}+w^{2}+h: s+h: w+w: s$

$0.81 \pm 0.03$

$26.9 \pm 0.3$

199.4

$\mathrm{h}+\mathrm{s}+\mathrm{w}+\mathrm{h}^{2}+\mathrm{h}: \mathrm{s}+\mathrm{h}: \mathrm{w} *$

$0.86 \pm 0.02$

$25.6 \pm 0.8$

195.8

BRT:

no interactions

$0.89 \pm 0.03$

$41.6 \pm 7.1$

n.a.

interactions

$0.90 \pm 0.02$

$42.4 \pm 3.6$

n.a.

\section{Ceriops tagal}

\section{GLM:}

hydroperiod

$0.73 \pm 0.04 \quad 15.2 \pm 0.4 \quad 205.9$

soil salinity

$0.56 \pm 0.06 \quad 0.8 \pm 0.1 \quad 240.1$

water salinity

$0.54 \pm 0.05 \quad 0.5 \pm 0.1 \quad 240.7$

$\mathrm{h}+\mathrm{s}+\mathrm{w}$

$0.76 \pm 0.05$

$17.3 \pm 0.5 \quad 205.4$

$h+s+w+h^{2}+s^{2}+w^{2}+h: s+h: w+w: s$

$0.82 \pm 0.04$

$35.1 \pm 0.2 \quad 175.8$

$h+s+w+h^{2}+s^{2}+h: s+h: w *$

$0.85 \pm 0.02 \quad 34.2 \pm 0.6$

172.9 


\section{BRT:}

no interactions

$0.84 \pm 0.02 \quad 28.7 \pm 4.7 \quad$ n.a.

interactions

$0.88 \pm 0.02 \quad 31.4 \pm 5.0$

n.a.

661

662 
663 Table 2. The estimated coefficient values ( \pm standard error) of the best models, as 664 indicated by Akaike's Information Criterion (AIC) for the GLMs of Sonneratia alba, 665 Rhizophora stylosa and Ceriops tagal dominance in Darwin Harbour. Interactions 666 between variables denoted by a colon and quadratic terms by a superscript 2. n.s. 667 indicates values not significant at $p<0.05$

668

\begin{tabular}{llll}
\hline Coefficient & S. alba & R. stylosa & C. tagal
\end{tabular}

\begin{tabular}{|c|c|c|c|}
\hline intercept & $-21.36 \pm 6.89$ & $-2.76 \pm 0.77$ & $-1.06 \pm 0.88$ \\
\hline hydroperiod & $0.96 \pm 0.28$ & $0.30 \pm 0.07$ & $-0.97 \pm 0.27$ \\
\hline soil salinity & $-0.77 \pm 0.25$ & $0.06 \pm 0.04$ n.s. & $0.54 \pm 0.14$ \\
\hline water salinity & & $0.02 \pm 0.02$ n.s. & $-0.03 \pm 0.03$ n.s. \\
\hline hydroperiod $^{2}$ & $-0.007 \pm 0.002$ & $-0.003 \pm 0.001$ & $0.002 \pm 0.001$ n.s. \\
\hline soil salinity $^{2}$ & & & $-0.02 \pm 0.01$ \\
\hline hydroperiod:soil salinity & & $0.007 \pm 0.003$ & $0.02 \pm 0.01$ \\
\hline hydroperiod:water salinity & & $-0.007 \pm 0.002$ & $0.02 \pm 0.01$ \\
\hline
\end{tabular}


671 Figure 1 Map of the study area showing the extent of the mangrove forest in Darwin

672 Harbour, northern Australia and location of sites surveyed. Inset map of Australia indicates

673 the location of Darwin Harbour.

674 Figure 2 Mean, standard error (indicated by boxes) and 95\% confidence intervals (indicated 675 by whiskers) for the explanatory variables (hydroperiod, soil salinity and wet season water 676 salinity) at sites dominated by Sonneratia alba (43 sites), Rhizophora stylosa (59 sites) and 677 Ceriops tagal (56 sites) in Darwin Harbour.

678 Figure 3 Partial dependence plots from BRT models, showing the relationship between the 679 probability of dominance of Sonneratia alba, Rhizophora stylosa or Ceriops tagal, and the 680 explanatory variables: hydroperiod (percent of time inundated), soil salinity (parts per 681 thousand, ppt) and the salinity of the inundating water in the wet season (ppt), for Darwin 682 Harbour. Relative variable importance represents the number of times a variable is selected 683 for splitting in the BRT algorithm and is scaled out of 100 (shown on each panel)

684 Figure 4 Plots showing the relationship between the probability of dominance of (a) Sonneratia alba, (b) Rhizophora stylosa or (c) Ceriops tagal, along two gradients: hydroperiod (percent of time inundated) and soil salinity (ppt), as derived from the BRT 687 models for Darwin Harbour. 


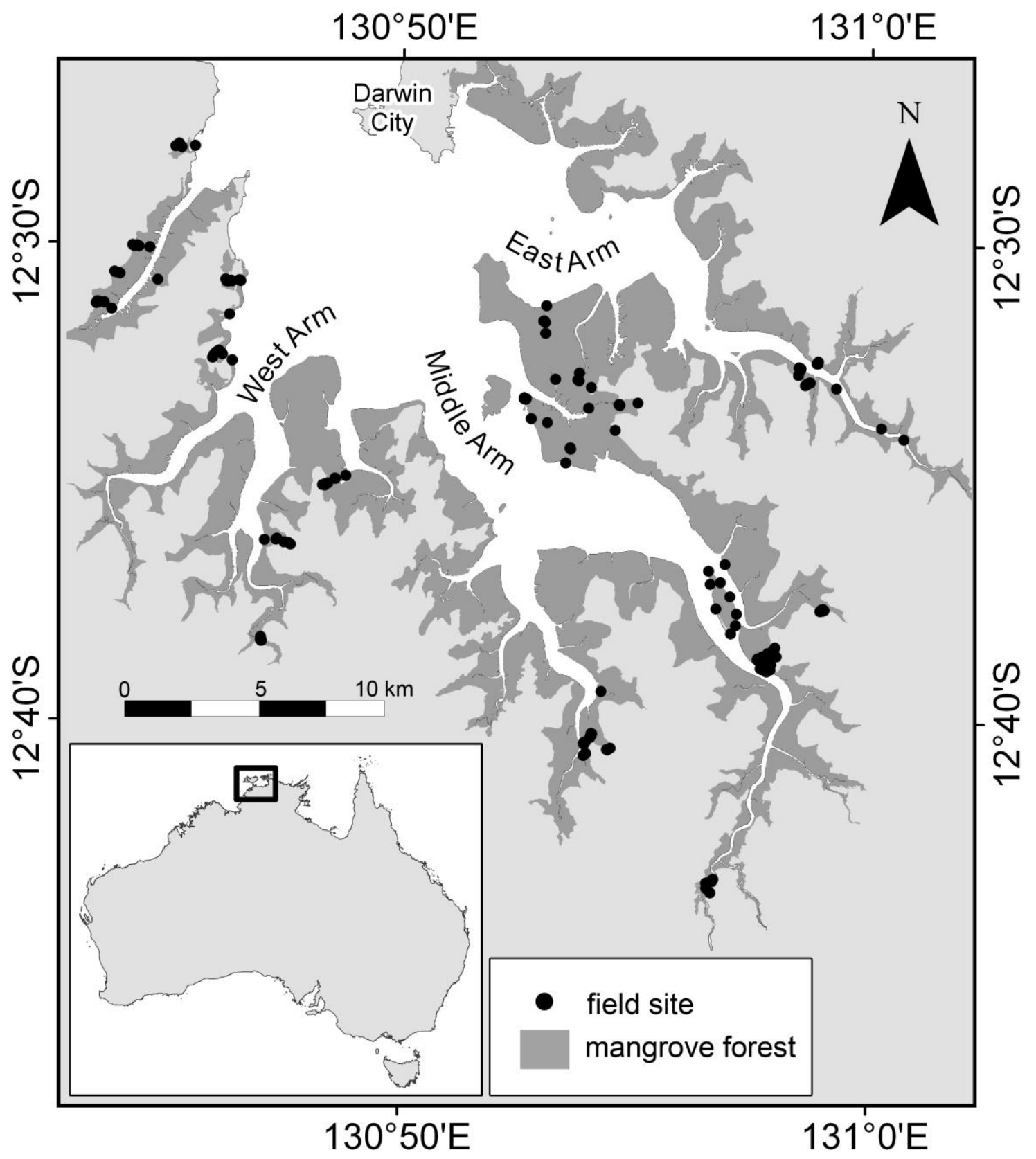

690

691 Figure 1 


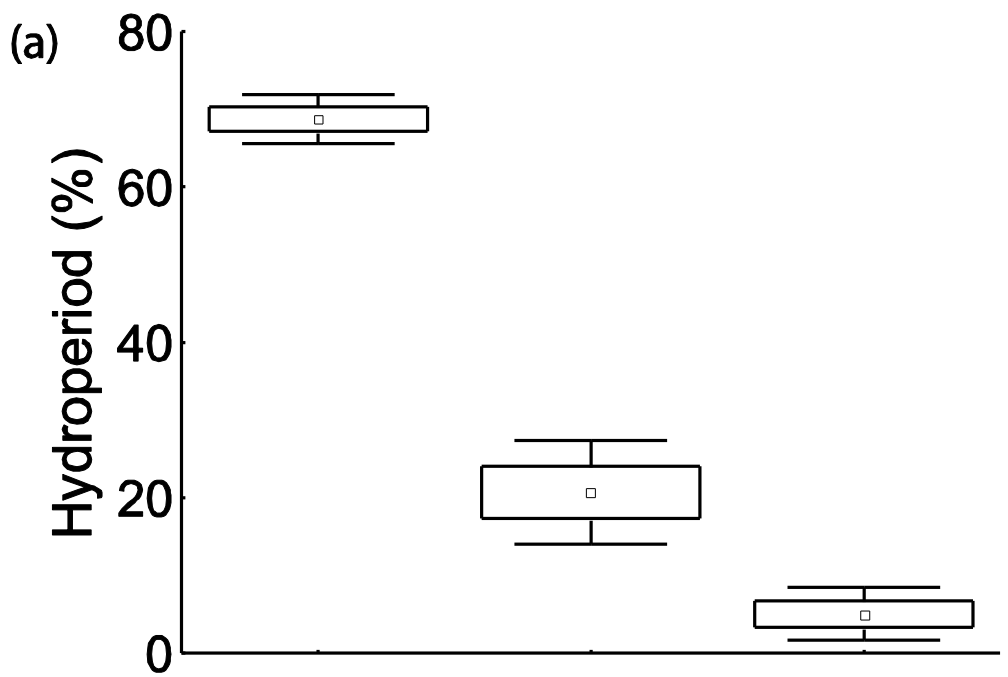

(b)
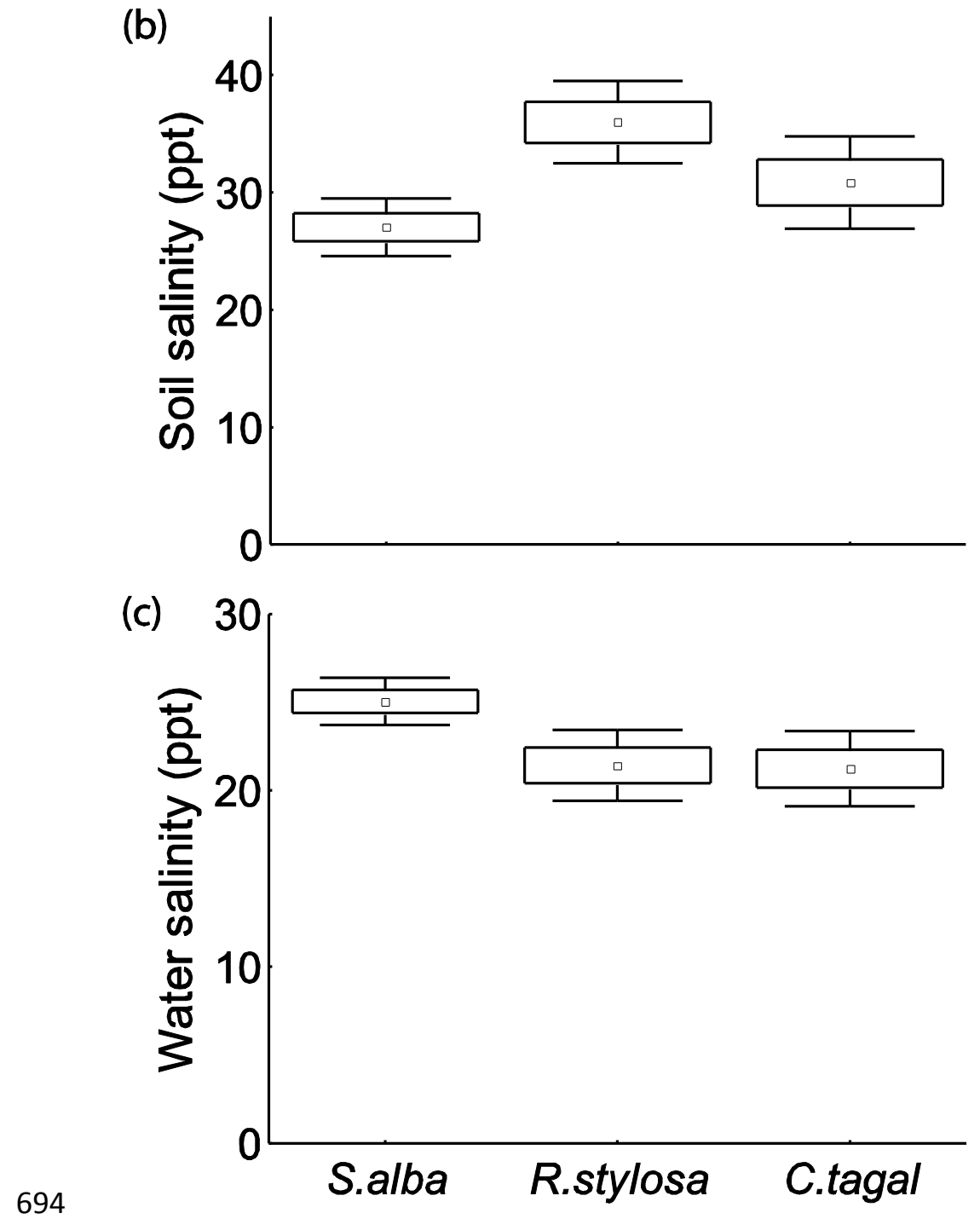

695 Figure 2 
697
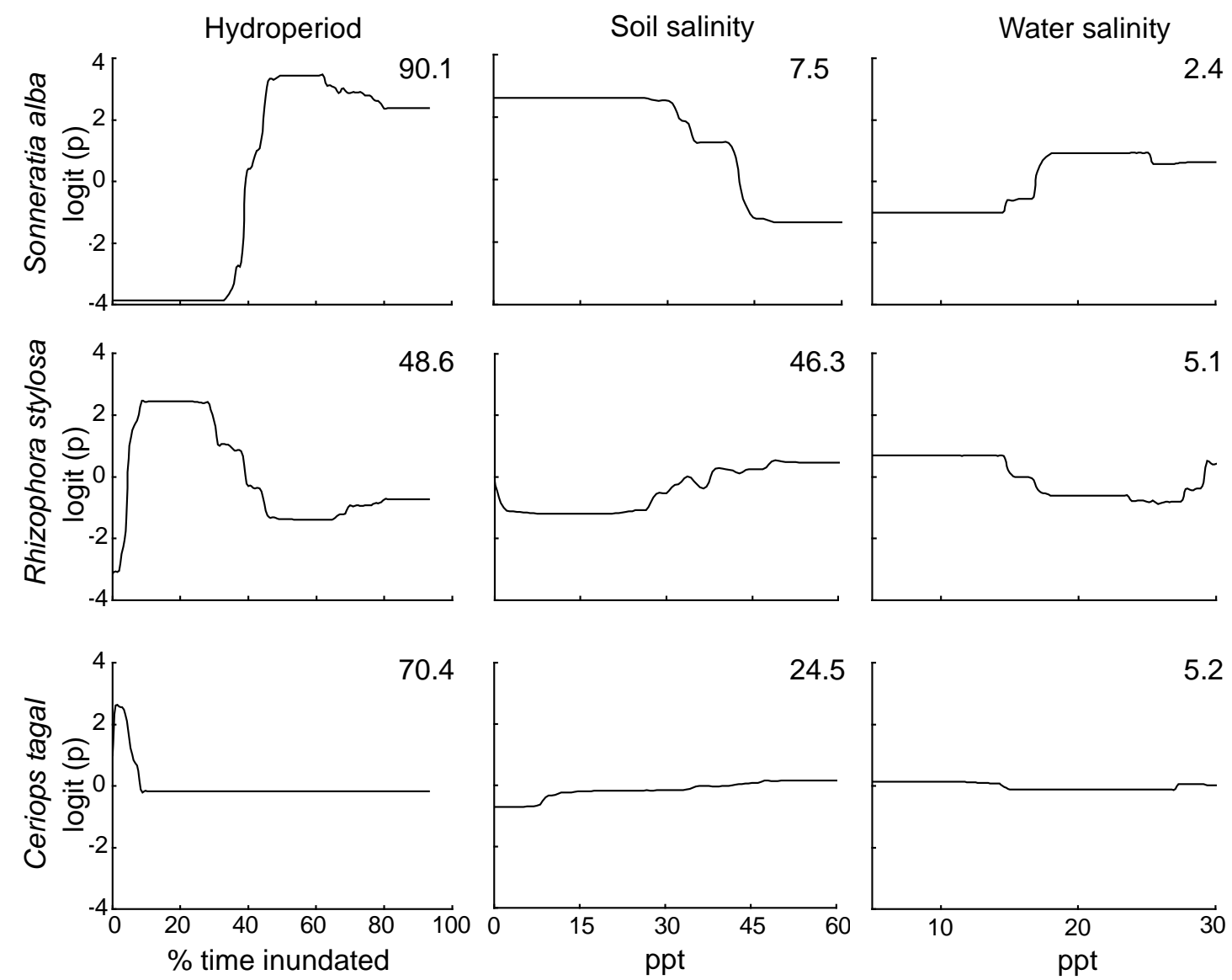

699

Figure 3 

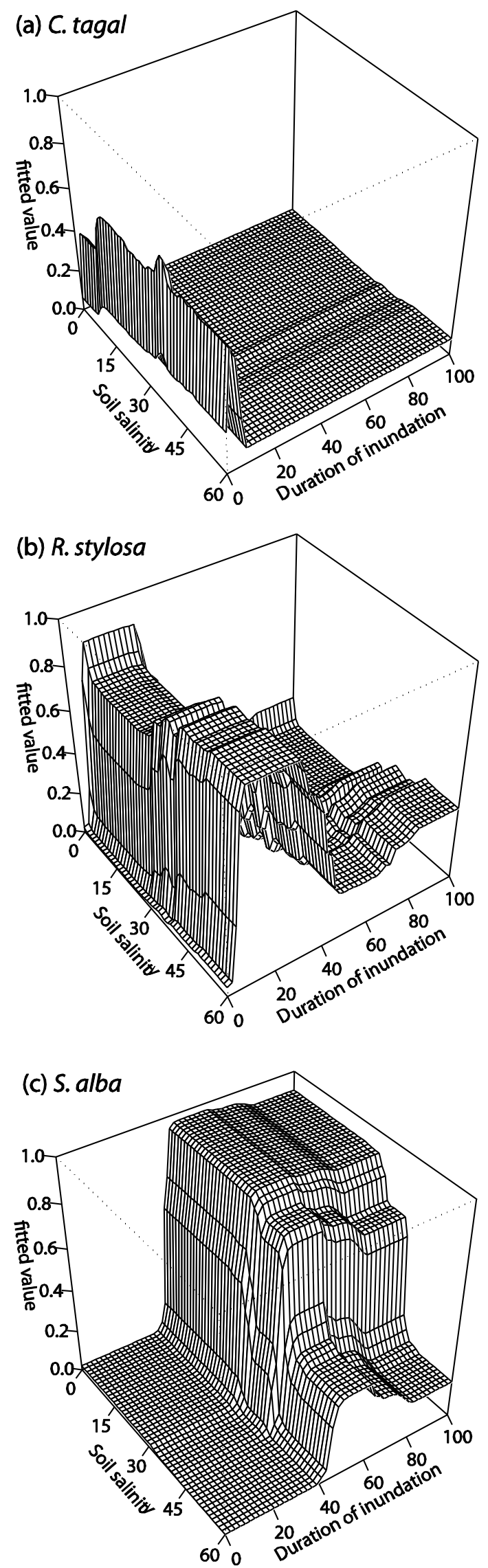